\title{
GESTÃO DE POLÍTICAS PÚBLICAS E SUAS IMPLICAÇÕES PARA A ÁREA DA SAÚDE
}

\author{
Micaela Gois Boechat Boaventura ${ }^{1}$ \\ Debora Cristina da Silva ${ }^{2}$
}

RESUMO: A implantação Políticas Públicas é uma urgência constante no Brasil, uma vez que o país tem atravessado momentos em que a população carece de mudanças nas mais variadas áreas. Em virtude disto, este trabalho justifica-se pelo fato de contribuir para que o conceito do tema seja amplamente difundido e compreendido, gerando, assim, uma grande reflexão diante das problemáticas sociais, que demandam da elaboração de políticas públicas, a fim de suprir as necessidades de uma nação, sobretudo quando se trata da área da Saúde, que sempre carece de uma atenção especial. Através do levantamento bibliográfico, objetivase fomentar as discussões acerca do tema supracitado, compreendendo, então, a importância das Políticas Públicas para o coletivo, de modo a suprir necessidades que, muitas vezes, são recorrentes, quando se referem ao bem-estar individual.

Palavras-chave: Gestão Pública. Políticas Públicas Saúde. SUS.

RESUME: The implementation of Public Policies is a constant urgency in Brazil, since the country has been going through times when the population lacks changes in the most varied areas. As a result, this work is justified by the fact that it contributes to the concept of the theme being widely disseminated and understood, thus generating a great reflection on the social problems that demand the elaboration of public policies in order to meet the needs of a nation, especially when it comes to the area of Health, which always needs special attention. Through the bibliographical survey, the objective is to encourage discussions on the aforementioned theme, understanding, then, the importance of Public Policies for the collective, in order to meet needs that are often recurrent, when referring to well-being individual.

Keywords: Public Management. Public Health Policies. SUS.

\footnotetext{
I Mestrado profissional em Ciências Ambientais- Universidade Federal do Paraná, UFPR, Brasil. Especialização em andamento em Auditória no SUS- Escola de Saúde Pública do Paraná, ESPP, Brasil. Especialização em Gestão e Auditoria em serviços da saúdeFaculdade Futura, ICETEC, Brasil. Especialização em Gestão Pública em Saúde- Faculdade Futura, ICETEC, Brasil. Especialização em Saúde da Família- Faculdade Futura, ICETEC, Brasil. Graduação em Saúde Coletiva- Universidade Federal do Paraná, UFPR, Brasil. E-mail: mica.goisı@gmail.com.

${ }^{2}$ Especialização em andamento em Zoonoses e Saúde Pública- Faculdade Unyleya, Brasil. Especialização em andamento em Clínica Médica e Cirúrgica de pequenos animais- Faculdade Qualittas, Curitiba. Especialização em Higiene e Inspeção de Produtos de Origem Animal promovido pela Sociedade Paranaense de Medicina Veterinária- Faculdade Spei, Brasil. Graduação em Medicina Veterinária- Pontifícia Universidade Católica do Paraná., PUC-PR. E-mail: deboracristina_silva@msn.com.
} 


\section{INTRODUÇÃO}

A área da Saúde, considerada de extrema complexidade, requer um olhar mais atento, considerando que a vida e o bem-estar de milhões de cidadãos, dependem de um serviço de qualidade.

Partindo de tal premissa, a Gestão de Políticas Públicas deve voltar-se a objetivos específicos, que norteiem a implantação de Políticas voltadas à saúde pública e, em especial, ao Sistema Único de Saúde (SUS), que deve atender devidamente aos usuários, sem quaisquer restrições, considerando sua universalização, preconizada em Constituição Federa, de acordo com França (1998).

Importa mencionar que Políticas Públicas são compostas de princípios e diretrizes norteadores de ação do Poder Público, a fim de reafirmar compromissos sociais, cuja resposta é oferecida pelo Estado, a fim de atender a uma necessidade manifestada pela sociedade, lançando mão de instrumentos para seu equacionamento e adotando planos de trabalho e programas condizentes com necessidades.

Dentre o rol de Políticas Públicas existentes, a Saúde representa uma resposta social de uma organização diante das condições de saúde dos sujeitos, validando que o SUS, como Política de Saúde Pública vigente no país, é o responsável maior pela distribuição, gestão e regulação de bens e serviços, que devem ser estudados em sua particularidade, tendo em vista sua relevância.

Assim, conhecendo a problemática que permeia a área da Saúde, cujo atendimento não supre necessidades vigentes, este estudo delimita-se ao conhecimento das Políticas brasileiras, no passado, comparando-as com esta Era, de modo a vislumbrar avanços ou retrocessos, no que diz respeito ao atendimento de pacientes que recorrem ao Sistema.

Durante muitos anos, o Brasil não apresentava qualquer tipo de estratégia para atender a esse tipo de demanda, sendo, historicamente, delegada à caridade, de modo a não oferecer direitos concisos para seu povo, no que diz respeito ao seu bem-estar.

Mediante mudanças, passou-se a considerar pontos necessários para a implantação de um Sistema eficaz que, de acordo com o levantamento bibliográfico, devidamente fundamentado, demonstrou surtir efeito para as mudanças e melhorias, ainda que mediante crises de ordem social, política e econômica, fazendo parecer não suficiente para um atendimento ainda não satisfatório. 
De qualquer forma, observam-se, através de dados, transformações concretas e necessárias, cujas Políticas têm contribuído para avanços na área da Saúde, conforme constata-se nesta pesquisa.

\section{DESENVOLVIMENTO}

\section{Políticas públicas: preceitos e impactos na sociedade}

A aglutinação das sociedades, compõe um conjunto de regras que forma a noção de Estado, visando à proteção de propriedades, bem como à regulação de atribuições, conforme assinala Bonavides (2000).

Nesse sentido, o autor pontua que o Estado é a ordem jurídica, caracterizado como corpo normativo, sendo exterior à sociedade, que é compreendida como esfera mais dilatada, em que os indivíduos dinamizam e expandem seu trabalho.

Para Pereira (2012), o Estado possui um papel com características paternalistas, visando à satisfação de lacunas institucionais, sociais e organizacionais e, diante de tal contexto, este controla conflitos de interesses entre os diversos atores presentes no ciclo de Políticas Públicas.

Já o Governo, de acordo com Rodrigues (2010), configura-se como instância máxima de administração executiva, a fim de direcionar Políticas Públicas e regular a sociedade.

As Políticas Públicas, assim, compõem a forma pela qual o governo executa suas ações, revestindo-se de autoridade soberana, acompanhadas de metas e objetivos relacionados ao estado de situações que se pretende alterar, através de estratégias de ação (PEREIRA, 2012).

As ações do Governo são fundamentadas nos interesses políticos e nas ideologias de diversos seguimentos da sociedade, em que se reúnem grupos sociais e empresários, para que o governo atenda a determinadas demandas.

Desde o ano de 1980 , as Políticas Públicas têm se intensificado no Brasil, seguindo as mudanças enfrentadas pelo país, com reformas econômicas e políticas, voltadas à saúde, educação, segurança e previdência, buscando compreender suas possiblidades de implementação (BONAVIDES, 200o).

Para Rodrigues (2010), o termo Políticas Públicas é expresso a partir do processo em que grupos com interesses divergentes, que tomam decisões coletivas, direcionando a 
sociedade. Já Souza (2006), expressa que as Políticas Públicas repercutem na economia e nas sociedades.

Destaca-se ainda que, segundo Frey (200o), para avaliar uma Política Pública, é essencial a compreensão da ordem do sistema político, levando em conta perspectivas neo institucionais. Analisar, ainda, o contexto dos atores e onde estão inseridos, são fatores fundamentais para a implementação de políticas em países de desenvolvimento.

Rodrigues (2010), salienta que as Políticas Públicas requerem avaliações que visam a decisões tomadas, bem como ao poder que o Governo exerce sobre a presença de determinada ocorrência.

Assim, Políticas Públicas, são explicadas através de vários enfoques, dada sua multidisciplinaridade, que caracteriza-se através da definição da agenda, formulação e implementação e avaliação do programa (FREY, 200o).

Destaca-se, também, que as etapas que envolvem o ciclo das políticas, são moldadas de acordo com variações intensas, que interferem na tomada de decisão, se estruturando em três formas distintas: a partir de problemas para formulação de soluções; por meio de ajustes dos problemas; disponibilidade de soluções que perseguem a detecção de problemas (RODRIGUES, 2010).

Considerando sua importância, conforme o exposto até aqui, é fundamental mencionar que somente após a Segunda Guerra Mundial, o Brasil passou a intervir no setor da Saúde através de financiamentos precários, demonstrando um certo desinteresse em voltar-se a esta necessidade de sua população (JUNIOR, 2006).

No período que vigorou até meados de 1960, o país não apresentava qualquer condição de eliminar doenças infecciosas e parasitárias, tampouco reduzir taxas de mortalidade infantil e adulta.

\section{Políticas públicas na saúde}

A formação cultura e econômica brasileira é fora marcada pela inexistência de Políticas públicas e, desde o período do Brasil Colônia, não se pensava no bem-estar da sociedade, tampouco na implantação de políticas em benefícios do social, delegando apenas à igreja o papel de cuidar de toda a população, de acordo com os estudos de Faoro (1985). 
Apenas com o Golpe Militar de 1964, de acordo com Bertolli Filho (1996), as Políticas de Saúde foram alteradas por imposição do Ministério da Saúde, com verbas destinadas à saúde pública, embora, com restrições para o individual, ao invés de se estenderem de forma coletiva.

$\mathrm{Na}$ década seguinte, por meio da $8^{\mathrm{a}}$ Conferência Nacional da Saúde, iniciou-se a implantação do Sistema Unificado e Descentralizado de Saúde, que resultava, ainda, em um convênio entre o INAMPS e os governos estaduais, somado, ainda, à definição, mediante Constituição Federal, de que a saúde se configurava como um direito de todos e dever do Estado, originando, assim, o Sistema Único de Saúde, sendo implantado de forma gradativa, conforme assevera Polignano (2006).

A partir de então, percebe-se uma certa preocupação em relação às Políticas Públicas voltadas à Saúde, de modo a atender, finalmente, aos usuários por meio de prestação de serviço gratuita.

Vale ressaltar que a Constituição Federal reconfigurou as Políticas na área, estabelecendo-se como direito universal e ampliando o financiamento do SUS, que historicamente se manteve sob responsabilidade da União, passando a contar com a participação de Estados e Municípios.

Importa mencionar que o SUS, através de princípios estabelecidos pela Lei Orgânica (BRASIL, 1990), apresenta as seguintes premissas: Atender a todos, de acordo com suas necessidades, e sem cobrar pelo atendimento; Atuar de modo em que suas ações sejam voltadas para o indivíduo e para a comunidade, de modo a oferecer prevenção e tratamento, priorizando a dignidade humana; ser racional, organizando serviços e ações para a população; ser eficaz e eficiente, produzindo resultados com qualidade; ser democrático, assegurando o direito de participação de todos os envolvidos.

Atualmente, de acordo com o levantamento de Santos (2007), o SUS transformouse no maior projeto público de inclusão social em menos de duas décadas, graças às Políticas voltadas à área da Saúde, mencionando:ıro milhões de pessoas atendidas por agentes comunitários de saúde em 95\% dos municípios, e 87 milhões atendidas por 27 mil equipes de Saúde de Família. 2,7 bilhões de procedimentos ambulatoriais, 6ro milhões de consultas e ı, 8 milhões de internações, que apresentaram considerável crescimento, 212 milhões de 
atendimentos odontológicos, 403 milhões de exames laboratoriais, 2,I milhões de partos, 13,4 milhões de ultrassons, tomografias e ressonâncias e 55 milhões de sessões de fisioterapias.

Evidentemente, são números impressionantes para a população atual, em marcante contraste com aproximadamente metade da população excluída antes dos anos 1980, a não ser pequena fração atendida eventualmente pela caridade, conforme esclarece o autor, comprovando a importância de tais Políticas Públicas, especialmente, na área da Saúde, que beneficiem ao maior número da população.

\section{Linha do tempo das Políticas Públicas em Saúde no Brasil}

No ano de 1923 foram criadas caixas de aposentadorias e pensões, atendendo ás demandas dos trabalhadores; 1932 Criação dos Institutos de Aposentadoria e Pensões, consolidando processos de industrialização e urbanização no Brasil; 1965 Criação do Instituto Nacional de Previdência Social, consolidando o componente assistencial hospitalocêntrico, curativista e médico-centrado; 1977 Sistema Nacional de Assistência e Previdência Social, prestador de assistência médica, que ainda se reproduz no Sistema Único de Saúde; 1982. Implantação do Sistema Nacional de Assistência e Previdência Social, visando à integração das instituições públicas da saúde mantidas pelas diferentes esferas de governo, em rede regionalizada e hierarquizada; 1990 Criação do Sistema Único de Saúde, visando sobre as condições para a promoção, proteção e recuperação da saúde, e a organização e o funcionamento dos serviços correspondentes.; 1994 Programa Saúde da Família, conhecido, atualmente, como Estratégia Saúde da Família (ESF), visando à reversão do modelo assistencial vigente, em que predomina o atendimento emergencial ao doente, na maioria das vezes em grandes hospitais.; 2006 Pacto da Saúde, conjunto de reformas institucionais pactuado entre as três esferas de gestão (União, estados e municípios) do Sistema Único de Saúde, com o objetivo de promover inovações nos processos e instrumentos de gestão; 2017 Atualização da Política Nacional de Atenção Básica; 2019 Previne Brasil, portaria que responsabiliza equipes e gestores para recebimento de recursos oriundas da Atenção Primária.

Neste contexto podemos observar a evolução das políticas e projetos de saúde que ganham força no decorrer do tempo, atualizando suas propostas adequando-as conforme as demandas sociais e melhor adequação dos recursos públicos de saúde. 


\section{Considerações finais}

Pensar em Políticas Públicas no Brasil, pode tornar-se um grande desafio, tendo em vista que, atualmente, as necessidades são muitas e, aparentemente, incontáveis.

Existe, atualmente, um grande corte de verbas em áreas essenciais, como Saúde e Educação, além de uma grave crise política e econômica, que divide opiniões.

Indo ainda mais além, num sentido mais crítico e reflexivo, mas, com este trabalho, surgem questionamentos, uma vez em que se aponta o Governo como um prestador de serviço para uma população, sendo, difícil de justificar o fato de alguns serviços terem sido retirados do povo.

Espera-se, sempre, entretanto, que a nação possa, ainda que eventualmente, beneficiar-se de projetos sociais, sendo essencial que se visasse ao bem-estar de um coletivo, de forma irrestrita, em que o Estado fosse total provedor de Políticas Públicas a fim de favorecer a toda uma população.

Verificou-se, contudo, que o SUS busca atender satisfatoriamente a população, considerando os dados aqui apresentados, entretanto há, ainda, a necessidade da reformulação constante de Políticas Públicas, tendo em vista que a sociedade é cíclica, bem como a demanda pela prestação destes serviços.

\section{Referências}

BERTOLLI - FILHO, Claudio; História da saúde pública no Brasil. São Paulo: Ática, I996. BONAVIDES, Paulo; Ciência Política. ı. ed. São Paulo: Malheiros, 2000

BRASIL. Lei Orgânica da Saúde. Dispõe sobre as condições para a promoção, proteção e recuperação da saúde, a organização e o funcionamento dos serviços correspondentes e dá outras providências. Disponível em: http://www.prattein.com.br/home/images/stories/Saude/Lei-org-saude.pdf. Acesso em: 13 dez. 2019.

CUNHA - GIANE- SOARES, Carla ; Avaliação de Políticas Públicas e Programas Governamentais: tendências recentes e experiências no Brasil. In: The TheoryandOperationof a ModernNationalEconomy. Washington: George Washington University, 2006. 
FAORO, Raymundo; Os donos do poder: formação do patronato político brasileiro. São Paulo: Globo. 1985 .

FRANÇA - BARBOZA, Susete ; A presença do estado no setor saúde no Brasil. Revista do Serviço Público, v. 49, n. 3, p. 85-10o, 1998

FREY, Klaus; Políticas públicas: um debate conceitual e reflexões referentes à prática da análise de políticas públicas no brasil. Planejamento e Políticas Públicas, n. 2I. p. 2II-26o, jun. 200o. Disponível em: 〈http://www.ipea.gov.br $>$ Acesso em: I4 dez. 2019.

JUNIOR, Aylton. Paulus. Políticas públicas de saúde no Brasil. Revista Espaço para a Saúde, Londrina, v. 8, n. I, p. 13-19, dez. 2006.

MATIAS- PEREIRA, José; Manual de gestão pública contemporânea. 4. ed. São Paulo: Atlas, 2012.

POLIGNANO, Marcus Vinícius; História das políticas de saúde no Brasil. 2006. Disponível em: 〈http://internatorural.medicina.ufmg.br/saude_no_brasil.pdf $>$. Acesso em: 13 dez. 2019.

RODRIGUES - ASSUMPÇÃO, Marta Maria; Políticas Públicas. São Paulo: Publifolha, 2010.

SANTOS- RODRIGUES, Nelson; Desenvolvimento do SUS, rumos estratégicos e estratégias para visualização de rumos. Ciênc. Saúde Coletiva. Rio de Janeiro, v. I2, n. 2, abr. 2007.

SOUZA, Celina; Políticas Públicas: uma revisão de literatura. Sociologias, Porto Alegre, v. 8, n. 16, p. 20-45, jul./dez. 2006. 